\title{
A preclinical evaluation of pemetrexed and irinotecan combination as second-line chemotherapy in pancreatic cancer
}

\author{
A Mercalli', V Sordi', R Formicola', M Dandrea ${ }^{2}$, S Beghelli', A Scarpa ${ }^{2}$, V Di Carlo', M Reni ${ }^{3,4}$ and \\ L Piemonti*,1,4
}

'Laboratory of Experimental Surgery, San Raffaele Scientific Institute, Via Olgettina 60, Milan 201 32, Italy; ${ }^{2}$ Section of Anatomic Pathology, Department of Pathology, University of Verona, Strada Le Grazie 8, Verona 37I 34, Italy; ${ }^{3}$ Department of Oncology, San Raffaele Scientific Institute, Via Olgettina 60, Milan 20132, Italy

Gemcitabine (GEM)-based chemotherapy is regarded as the standard treatment of pancreatic adenocarcinoma, but yields a very limited disease control. Very few studies have investigated salvage chemotherapy after failure of GEM or GEM-containing chemotherapy and preclinical studies attempting to widen the therapeutic armamentarium, not including GEM, are warranted. MIA PaCa2, CFPAC-I and Capan-I pancreatic cancer cell lines were treated with GEM, fluouracil (5-FU), docetaxel (DCT), oxaliplatin $(\mathrm{OXP})$, irinotecan (CPT-I I), pemetrexed (PMX) and raltitrexed (RTX) as single agent. Pemetrexed, inducing apoptosis with I $\mathrm{C}_{50} \mathrm{~S}$ under the $C_{\max }$ in the three lines tested, appeared the most effective drug as single agent. Based on these results, schedule- and concentration-dependent drug interactions (assessed using the combination index) of PMX/GEM, PMX/DCT and PMX-CPT-I I were evaluated. The combinatory study clearly indicated the PMX and CPT-II combination as the most active against pancreatic cancer. To confirm the efficacy of PMX-CPT-I I combination, we extended the study to a panel of 10 pancreatic cancer cell lines using clinically relevant concentrations (PMX $10 \mu \mathrm{M} ; \mathrm{CPT}-\mathrm{I}$ I I $\mu \mathrm{m}$ ). In eight of 10 lines, the PMX-CPT-I I treatment significantly reduced cell recovery and increased both the subGI and caspase 3/7 fraction. After a 5-day wash out period, an increased fraction of subGI and caspase3/7 persisted in PMX-CPT-I I-pretreated cell lines and a significant reduction in the clonogenicity capacity was evident. Finally, in vivo, the PMX/CPT-I I combination showed the ability to inhibit xenograft tumours growth as second-line therapy after GEM treatment. The PMX and CPT-I I combination displays a strong schedule-independent synergistic cytotoxic activity against pancreatic cancer, providing experimental basis for its clinical testing as salvage chemotherapy in pancreatic cancer patients. British Journal of Cancer (2007) 96, I358-1367. doi: 10. I038/s.bjc.6603726 www.bjcancer.com

Published online 10 April 2007

(C) 2007 Cancer Research UK

Keywords: pancreatic cancer; chemiosensitivity; human

Until a decade ago, the use of chemotherapy in pancreatic cancer was believed to have no role in the routine treatment of patients with advanced disease (Lionetto et al, 1995). To date, some options are available for first-line treatment (Burris et al, 1997; Reni et al, 2005). Single-agent fluorouracil (5-FU) results in tumour response rates of $7 \%$ or less (Cullinan et al, 1990; Burris et al, 1997). Combination chemotherapy with 5-FU has resulted in increased toxicity without higher efficacy (Schnall and Macdonald, 1996; Ducreux et al, 2002; Maisey et al, 2002; Beger et al, 2003). Gemcitabine (GEM) in weekly infusions has been shown to be superior to bolus 5-FU as monotherapy for advanced disease in a randomised phase III study and was licensed for treatment of advanced pancreatic cancer (Burris et al, 1997). Also a comprehensive experience reported in a large, multicentre, open-label study that enrolled more than 3000 patients on a compassionateneed basis documented single-agent GEM to be reasonably safe and to offer a median overall survival of 4.8 months (Storniolo et al, 1999). So GEM is currently regarded as the standard

*Correspondence: Dr L Piemonti; E-mail: piemonti.lorenzo@hsr.it

${ }^{4}$ These two authors contributed equally to this work.

Revised 5 March 2007; accepted 8 March 2007; published online 10 April 2007 treatment for advanced disease, and has led to an objective response in $4-26 \%$ of patients and a 1-year overall survival of $17-$ $28 \%$ of patients in phase III trials (Burris et al, 1997; Bramhall et al, 2001; Berlin et al, 2002; Bramhall et al, 2002; Heinemann, 2002; Moore et al, 2003; Rocha Lima et al, 2004; Van Cutsem et al, 2004; Reni et al, 2005).

Despite the fact that randomised studies have suggested that chemotherapy is superior to best supportive care in prolonging survival and improving symptoms in patients with advanced disease, standard single-agent GEM yields a marginal impact on disease outcome. Several attempts to improve the efficacy of GEM in advanced pancreatic adenocarcinoma by addition of a second cytotoxic agent or other drugs to a standard dose and schedule of GEM have not shown a significant survival advantage (Burris et al, 1997; Bramhall et al, 2001; Berlin et al, 2002; Bramhall et al, 2002; Heinemann, 2002; Moore et al, 2003; Rocha Lima et al, 2004; Van Cutsem et al, 2004; Mishra et al, 2005; Reni et al, 2005; Stathopoulos et al, 2006). GEM-based chemotherapy yields a very limited disease control, and progression usually occurs within a few months after first-line treatment starts. Median progressionfree survival with single-agent GEM is approximately 3 months and less than $15 \%$ of patients are progression free at 6 months from diagnosis (Burris et al, 1997; Bramhall et al, 2001; Berlin et al, 
2002; Bramhall et al, 2002; Heinemann, 2002; Moore et al, 2003; Rocha Lima et al, 2004; Van Cutsem et al, 2004; Reni et al, 2005). In spite of progressive disease, about half of the patients maintain a good performance status and are willing to undergo further treatment. So far very few studies have investigated salvage chemotherapy after failure of GEM or GEM-containing chemotherapy (Oettle et al, 2000; Ulrich-Pur et al, 2003; Cantore et al, 2004; Milella et al, 2004; Reni et al, 2004). As no standard therapeutic option exists and scarce information on the impact on outcome of salvage therapy is available from the literature, preclinical studies attempting to widen the therapeutic armamentarium, not including GEM, are warranted.

The present study was performed in pancreatic cancer lines to identify GEM-free combination of drugs. The PMX and CPT-11 combination showed a strong schedule-independent synergistic cytotoxic activity against pancreatic cancer, providing experimental basis for its clinical testing as salvage chemotherapy in pancreatic cancer patients.

\section{MATERIALS AND METHODS}

\section{Drug and chemical}

GEM and PMX were from Eli Lilly (Indianapolis, IN, USA), RTX was from AstraZeneca (Basiglio, Italy), OXP from Sanofi Synthelabo (Milan, Italy), DCT and CPT-11 from Aventis (Milan, Italy), 5-FU from Teva Pharma Italia (Milan, Italy). Drugs were dissolved in sterile distilled water and diluted in culture medium immediately before use.

\section{Drug pharamacokinetics}

The data on the pharmacokinetics of the drugs $\left(C_{\max }\right)$ in human were obtained by the revision of the earlier publications (Abbruzzese et al, 1991; Burris et al, 1993; Extra et al, 1993; Pazdur et al, 1993; Rothenberg et al, 1993; Clarke et al, 1996; Chabot, 1997; Hui and Reitz, 1997; Beale et al, 1998; Gamelin et al, 1998; Judson et al, 1998; O’Dwyer et al, 1999; Rinaldi, 1999; Culy et al, 2000; Jodrell et al, 2001).

\section{Cell culture}

Pancreatic cancer cell lines MIA PaCa2, CFPAC-1, HS766T, T3M4, A818-4 (American Type Culture Collection, Manassas, VA, USA), Capan-1, PaCa3, SK-PC 1, PANC-2, PC (generous gift from Professor A Scarpa, University of Verona, Verona, Italy) were cultured as monolayers in RPMI 1640 (Biochrom, Berlin, Germany), supplemented with 10\% heat-inactivated FCS (Hyclone, Logan, UT, USA), penicillin and streptomycin $\left(100 \mu \mathrm{g} \mathrm{ml}^{-1}\right)$ under standard culture conditions $\left(5 \% \mathrm{CO}_{2}, 95 \%\right.$ air in humidified chamber at $37^{\circ} \mathrm{C}$ ). Cells were cultivated in $72 \mathrm{~cm}^{2}$ flasks (Costar, Cambridge, MA, USA) and were harvested with trypsin when they were in logarithmic growth.

\section{Cell cycle, apoptosis analysis, clonogeneic capacity}

Cells were plated in 24-well sterile plastic plates (Costar) at $15 \times 10^{4}$ cell ml $^{-1}$ and were allowed to attach for $24 \mathrm{~h}$. Then, cells were treated with different concentration $(0.001-100 \mu \mathrm{M})$ and combination of GEM, 5-FU, DCT, OXP, CPT-11, PMX and RTX for $48 \mathrm{~h}$. After drug treatment, cells were trypsinised, washed once with PBS, and fixed with $70 \%$ ethanol at $-20^{\circ} \mathrm{C}$ for $24 \mathrm{~h}$. Fixed cells were washed three times and stained with a propidium iodide (PI; Sigma Chemical Co., St Louis, MO, USA) solution $\left(20 \mu \mathrm{g} \mathrm{ml}^{-1}\right)$ containing $0.1 \mathrm{mg} \mathrm{ml}^{-1}$ of RNase A (Sigma Chemical Co., St Louis, MO, USA). Cells were then subjected to cell cycle analysis for determining DNA contents by flow cytometry (FACScan, Cell Quest software; BD Biosciences, San Jose, CA, USA). Cell debris was excluded on the basis of forward $v s$ side scatter. Doublets and clumps were excluded by gating on a bivariate distribution of AUX (PI peak pulse) $v s$ the PI-integrated signal. Data from 10000 events were collected in the final gated histograms. Apoptotic cells were identified on the basis of hypodiploid DNA content $\left(\mathrm{subG}_{1}\right.$ fraction) that results from DNA fragmentation and confirmed with the evaluation of phosphatidylserine exposure using annexin V-FITC Kit (Bender MedSystems, San Bruno, CA, USA) in combination with PI.

The activation of caspase 3/7 was analysed after drug treatment using Carboxyfluorescein FLICA Assay Kits (B-Bridge International, Inc., Sunnyvale, CA, USA) according to the manufacturer's instructions.

For the clonogenicity assay, cells were exposed for $48 \mathrm{~h}$ to the drug; then cells were washed, plated by limiting dilution down to three cell per well and cultured with drug-free fresh medium. After 1 week, each well was checked by optical microscopy for growing colonies (at least four cells per well).

The $\mathrm{IC}_{50}$ was defined as the drug concentration required to induce $50 \%$ of apoptotic cells and was calculated by nonlinear least-square curve fitting. Drug interaction was assessed at different concentration ratio $(0.1: 1 ; 1: 1 ; 10: 1)$ using the combination index (CI; Chou et al, 1994), where $\mathrm{CI}<1, \mathrm{CI}=1$ and $\mathrm{CI}>1$ indicate synergistic, additive and antagonistic effects, respectively.

Since several preclinical studies have shown a scheduledependent drug interaction for the antimetabolites in combination regimens (Tolis et al, 1999; van Moorsel et al, 1999; Peters et al, 2000; Edelman et al, 2001; Symon et al, 2002; Giovannetti et al, 2004), we tested, in vitro, different treatment schedules. For the experiments of sequential exposure, cells were treated with (a) drug $1(0.001-100 \mu \mathrm{M})$ for $48 \mathrm{~h}$; (b) drug $2(0.001-100 \mu \mathrm{M})$ for $48 \mathrm{~h}$; (c) drug 1 together with drug $2(0.001-100 \mu \mathrm{M}$, ratio $1: 1)$ for $48 \mathrm{~h}$; (d) drug $1(0.001-100 \mu \mathrm{M})$ for $24 \mathrm{~h}$ followed by drug 2 for $24 \mathrm{~h}$ (ratio1:1); (e) the reverse sequence of point (d). On the basis of the isobologram analysis for mutually exclusive effects, the CI value was calculated as follows:

$$
\mathrm{CI}=(D)_{1} /\left(D_{x}\right)_{1}+(D)_{2} /\left(D_{x}\right)_{2}
$$

where $\left(D_{x}\right)_{1}$ and $\left(D_{x}\right)_{2}$ are the concentrations of the single drugs required to induce cell apoptosis by $50 \%$, and $(D)_{1}$ and $(D)_{2}$ are the drug concentrations in combination treatments which also induce cell apoptosis by $50 \%$ (isoeffective as compared with single drugs). In some experiments, a nonconstant ratio combination design was used and the CI value for each data point was calculated. Data analysis was performed by the Calcusyn Software (Biosoft, Oxford, UK).

\section{In vivo study}

MIA PaCa2, CFPAC- 1 and PaCa3 cells $\left(5 \times 10^{6}\right.$ cells for each mice) were s.c. injected into female nude mice (4 weeks of age, Harlan, Italy). One week after cell inoculation (day 0), five randomised animals for each experimental group received GEM $\left(150 \mathrm{mg} \mathrm{kg}^{-1}\right.$ i.p.) at day $0,+3,+6,+9,+12,+15,+18$ and +21 or GEM $\left(150 \mathrm{mg} \mathrm{kg}^{-1}\right.$ i.p.) at day $0,+3,+6$ and +9 and then PMX $\left(100 \mathrm{mg} \mathrm{kg}^{-1}\right.$ i.p.) every day starting from day +12 until day +21 plus CPT-11 (50 $\mathrm{mg} \mathrm{kg}^{-1}$ i.p.) at day +12 and +17 . Control group received only the vehicle (PBS i.p.) at the same time. Tumour volume and body weight were daily recorded for each animal for all the period of drug treatments (day $0-21$ ) and for 10 days after treatment suspension (days 22-32). Tumour volume was calculated using the formula: $V=\pi / 6 \times$ (largest diameter $\times$ smallest diameter $)^{3 / 2}$. The ethical standards of the experiment were approved by the Verona University Review Board, and the animals were maintained in accordance with institutional guidelines. 


\section{Statistical analysis}

Data were expressed as mean values + s.d. or median $\left(25-75^{\circ}\right.$ percentiles). Differences between the $\mathrm{IC}_{50}$ were analysed by Wilcoxon Signed Ranks test. The potential of drugs for inhibition of in vivo tumour growth was analysed using Tukey's HSD test. Statistical analyses were performed using the Statistical Package for Social Science (SPSS 11.0; SPSS, Chicago, IL, USA).

\section{RESULTS}

Induction of apoptosis by GEM, 5-FU, DCT, OXP, CPT-11, PMX and RTX in pancreatic cancer cell lines: a comparative evaluation in relation with the 'in vivo' plasma maximum concentration $\left(C_{\max }\right)$ of the single drugs

MIA PaCa2, CFPAC-1 and Capan-1 pancreatic cancer cell lines were treated with GEM, fluouracil (5-FU), docetaxel (DCT), oxaliplatin (OXP), irinotecan (CPT-11), pemetrexed (PMX) and raltitrexed (RTX) as single agent. The efficacy of the drugs was evaluated considering the $50 \%$ induction apoptosis concentration $\left(\mathrm{IC}_{50}\right)$ in relation with the $C_{\max }$ (Figure 1 ). The majority of the $\mathrm{IC}_{50} \mathrm{~s}$ measured resulted abundantly over the $C_{\max } \mathrm{s}$ of the drugs, confirming pancreatic cancer as a chemoresistant tumour. A dosedependent induction of apoptosis with $\mathrm{IC}_{50}$ under the $C_{\max }$ in all the three lines tested was observed only by using PMX $\left(C_{\max }\right.$ $229 \mu \mathrm{M}$; median $\mathrm{IC}_{50}: 67.16,2.54$ and $27.12 \mu \mathrm{M}$, respectively, for MIA-PaCa2, CFPAC-1 and Capan- $1 ; n=12$ ). Two lines of three showed $\mathrm{IC}_{50}$ under $C_{\max }$ in the presence of DCT $\left(C_{\max } 0.99 \mu \mathrm{M}\right.$; median $\mathrm{IC}_{50}: 0.48,0.1147$ and $8109 \mu \mathrm{M}$, respectively, for MIAPaCa2, CFPAC-1 and Capan-1; $n=12$ ). One line of three showed $\mathrm{IC}_{50}$ under $C_{\max }$ in the presence of RTX $\left(C_{\max } 1.54 \mu \mathrm{m}\right.$; median $\mathrm{IC}_{50}: 27.77,7.37$ and $0.86 \mu \mathrm{M}$, respectively, for MIA-PaCa2, CFPAC1 and Capan- $1 ; n=12)$, OXP $\left(C_{\max } 2.05 \mu \mathrm{M}\right.$; median $\mathrm{IC}_{50}: 312,0.57$ and $6.58 \mu \mathrm{M}$, respectively, for MIA-PaCa2, CFPAC-1 and Capan-1; $n=12)$, GEM $\left(C_{\max } 61 \mu \mathrm{M}\right.$; median $\mathrm{IC}_{50}: 2.49,72.48$ and $559 \mu \mathrm{M}$, respectively, for MIA-PaCa2, CFPAC- 1 and Capan-1; $n=12$ ) and 5-FU $\left(C_{\max } 372 \mu \mathrm{M}\right.$; median $\mathrm{IC}_{50}: 26.19,>10000$ and $1750 \mu \mathrm{M}$, respectively, for MIA-PaCa2, CFPAC-1 and Capan-1; $n=12$ ).

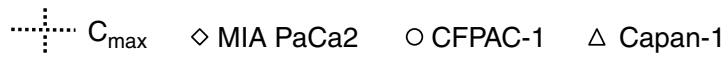

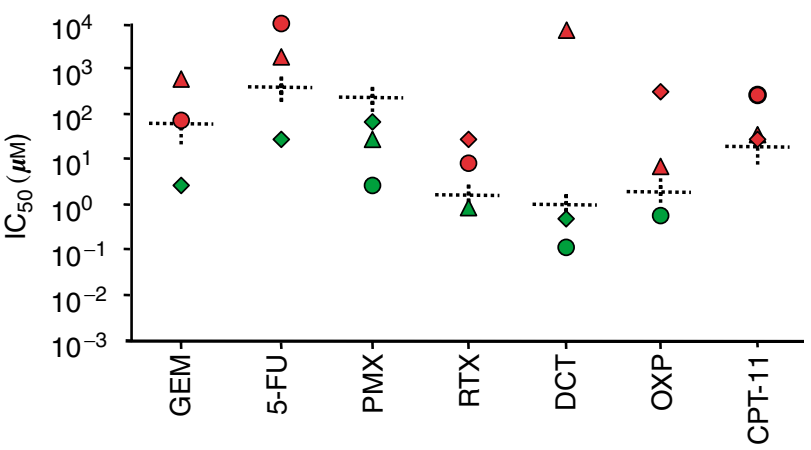

Figure I Drug concentrations required to induce the 50\% apoptotic cells $\left(\mathrm{IC}_{50}\right)$ in culture. MIA PaCa2, CFPAC-I and Capan-I pancreatic cancer cell lines were treated with gemcitabine (GEM), fluorouracil (5-FU), docetaxel (DCT), oxaliplatin (OXP), irinotecan (CPT-II), pemetrexed $(P M X)$ and raltitrexed (RTX) for $48 \mathrm{~h}$ with different concentration $(0.001-$ $100 \mu \mathrm{M})$. Data are expressed as median of 12 experiments. The plasma maximum concentration of the drugs $\left(C_{\max }\right)$ as described by human pharmacokinetics studies (Abbruzzese et al, 1991; Burris et al, 1993; Extra et al, 1993; Pazdur et al, 1993; Rothenberg et al, 1993; Clarke et al, 1996; Chabot, 1997; Hui and Reitz, 1997; Beale et al, 1998; Gamelin et al, 1998; Judson et al, 1998; O'Dwyer et al, 1999; Rinaldi, 1999; Culy et al, 2000; Jodrell et al, 200 I) was also reported. Red colour-filled symbol: $\mid C_{50}>C_{\text {max; }}$; green colour-filled symbol: $\mathrm{IC}_{50}<\mathrm{C}_{\max }$.
Finally, no lines showed $\mathrm{IC}_{50}$ under $C_{\max }$ in the presence of CPT-11 $\left(C_{\max } 16.05 \mu \mathrm{M}\right.$; median $\mathrm{IC}_{50}: 25.64,232$ and $30.33 \mu \mathrm{M}$, respectively, for MIA-PaCa2, CFPAC-1 and Capan- $1 ; n=12$ ).

\section{Study of PMX/GEM, PMX/DCT and PMX/CPT-11 combination}

We chose PMX as the drug to be tested in combination studies, since it appeared the most efficient drug in inducing apoptosis as single agent. We assessed the interaction of PMX with GEM (antimetabolite), DCT (antimicrotubule agent) and CPT-11 (topoisomerase inhibitors) in a constant ratio combination experimental design. We used three different concentration ratios for the study $(10: 1 ; 1: 1 ; 0.1: 1)$.

$\diamond$ MIA PaCa $2 \quad$ O CFPAC-1 $\Delta$ Capan-1
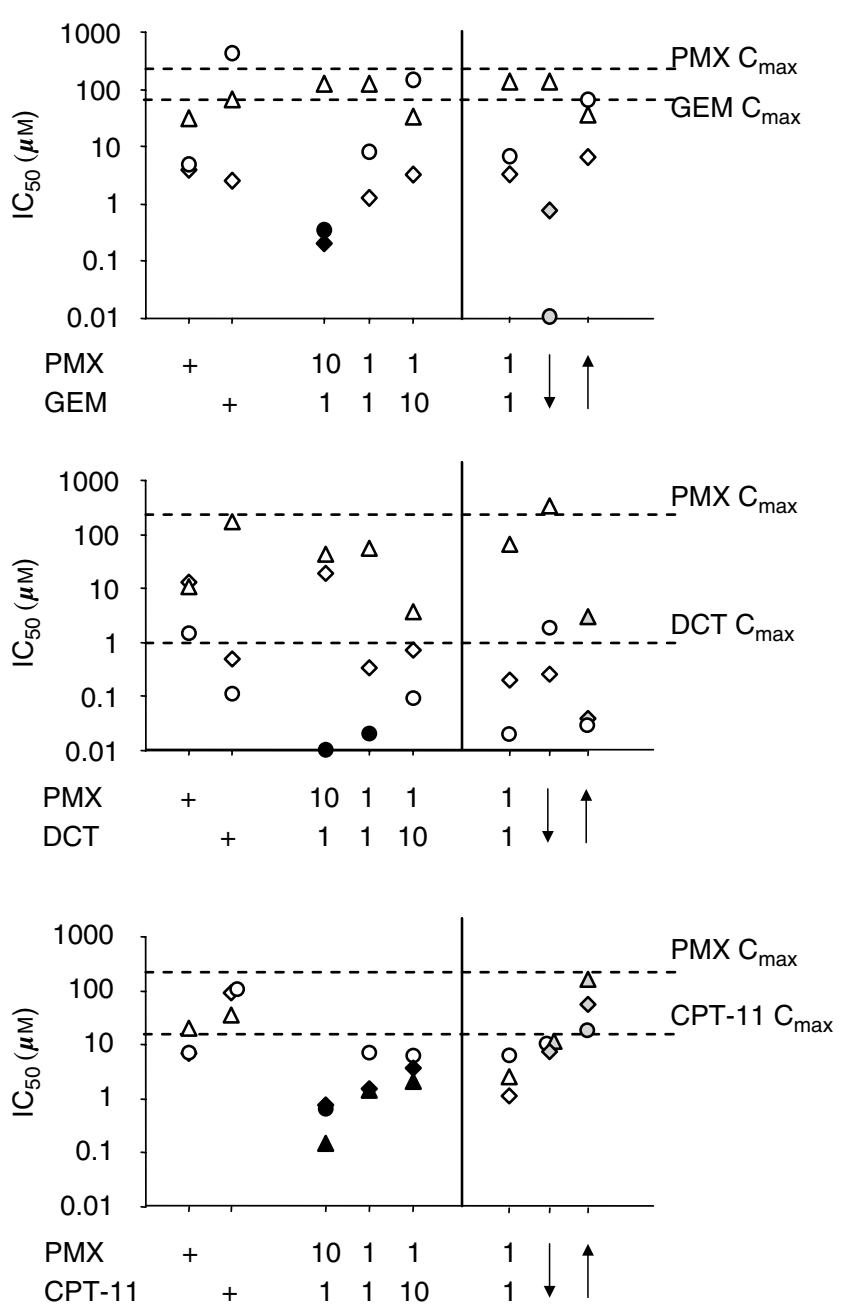

Figure 2 The $\mathrm{IC}_{50} \mathrm{~S}(\mu \mathrm{M})$ of $\mathrm{PMX}-\mathrm{GEM}, \mathrm{PMX}-\mathrm{DCT}$ and $\mathrm{PMX}-\mathrm{CPT}$ I | combinations. The $10: 1,1: \mid$ and $1: 10$ concentration ratio of $P M X$ GEM, PMX/DCT and PMX/CPT-II combinations were represented. Moreover, MIA PaCa2, CFPAC-I and Capan-I pancreatic cancer cell lines were treated with (a) PMX together with GEM, DCT or CPT-I I (0.00 I $100 \mu \mathrm{M}$, ratio I : I) for $48 \mathrm{~h}$; (b) PMX $(0.00 \mathrm{I}-100 \mu \mathrm{M})$ for $24 \mathrm{~h}$ followed by GEM, DCT or CPT-II for $24 \mathrm{~h}$ (ratiol: I); (c) the reverse sequence of point (b). The $I C_{50}$ values of the different ratio and sequences were calculated and reported. All the values are expressed as medians of six experiments. Black colour-filled symbol $=\mid C_{50}$ significantly less than the $\mathrm{IC}_{50} \mathrm{~S}$ of the single drug $(P<0.05$, Wilcoxon Signed Ranks test). Grey colour-filled symbol $=I C_{50}$ significantly less than the $I C_{50}$ of the simultaneous exposure for $48 \mathrm{~h}(P<0.05$, Wilcoxon Signed Ranks test). Dotted lines: $C_{\max }$ of GEM, DCT, CPT-II and PMX. 
The simultaneous exposure to PMX and CPT-11 appeared the most efficient combination in inducing apoptosis with $\mathrm{IC}_{50}$ less than the $\mathrm{IC}_{50} \mathrm{~s}$ of the single drugs in all the lines tested (Figure 2). The effect appeared particularly strong at the $10: 1$ ratio (but it is also present at 1:1 and 1:10 ratio) and the calculation of the CI showed synergism at effect levels obtainable with concentration under the $C_{\max }$ of CPT-11 and PMX (Figure 3).

The PMX-GEM combination appeared efficient in inducing apoptosis $\left(\mathrm{IC}_{50}\right.$ less than the $\mathrm{IC}_{50}$ of the single drugs) in two of three lines tested at the 10:1 ratio concentration (Figure 2), and the CI values at the same ratio showed synergism at concentrations under the $C_{\max }$ of GEM and PMX (Figure 2). At 1:1 ratio concentration, an additive (MIA PaCa2, Capan-1) or antagonistic (CFPAC-1) effect was present (Figure 3).

Finally, the effect of DCT in combination with PMX was variable and cell line dependent (Figures 2 and 3). CFPAC-1 cell line appeared sensitive to the action of DCT - PMX combination $\left(\mathrm{IC}_{50}\right.$ less than the $\mathrm{IC}_{50} \mathrm{~s}$ of the single drugs at $10: 1$ and $1: 1$ ratios tested and strong synergism both at $10: 1$ and $1: 1$ ratios), while, on the contrary, Capan-1 appeared resistant (no reduction of $\mathrm{IC}_{50} \mathrm{~s}$ at any ratio tested and $\mathrm{CI}$ indicating substantially an antagonism). MIA $\mathrm{PaCa} 2$ cell line showed an intermediate level of sensitivity.

The interaction of PMX with GEM, DCT and CPT-11 was also tested in a nonconstant ratio combination design varying the concentrations of each drug from 0.01 to $10 \mu \mathrm{m}$. As long as the shape of the dose-effect curve and the median effect dose parameters for each single drug are available, the CI values for each data point of the nonconstant ratio design were calculated (Chou et al, 1994). The nonconstant ratio combination experiments confirmed the results of the constant ratio experiments and in particular the strong synergistic effect of PMX and CPT-11 in all the lines tested (Figure 4).

Study of the schedule-dependent activity of PMX-GEM, PMX-DCT and PMX-CPT-11 combination

Cell lines were treated with (a) PMX together with GEM, DCT or CPT-11 $(0.001-100 \mu \mathrm{M}$, ratio $1: 1)$ for $48 \mathrm{~h}$; (b) PMX $(0.001-$
$100 \mu \mathrm{M})$ for $24 \mathrm{~h}$ followed by GEM, DCT or CPT-11 for $24 \mathrm{~h}$ (ratio1:1); (c) the reverse sequence of point (b). The $\mathrm{IC}_{50}$ and $\mathrm{CI}$ values of the different sequences were calculated (Figures 2 and 5).

The sequential exposure to PMX followed by GEM (PMX $\rightarrow$ GEM) appeared more efficient in inducing apoptosis than the reverse sequence $(\mathrm{GEM} \rightarrow \mathrm{PMX})$ in CFPAC-1 and MIA PaCa2 lines, while this schedule of treatment appeared substantially indifferent in Capan-1 line (Figure 2). The CI calculation confirmed in CFPAC-1 line the synergism for PMX $\rightarrow$ GEM sequence at effect level obtainable with concentration under the $C_{\max }$ of GEM, while the GEM $\rightarrow$ PMX sequence produced antagonism in all the lines tested (Figure 5).

For the PMX-DCT combination, DCT followed by PMX $(\mathrm{DCT} \rightarrow \mathrm{PMX}$ ) was more efficient in inducing apoptosis than the reverse sequence (PMX $\rightarrow \mathrm{DCT})$. DCT $\rightarrow$ PMX sequence reduced the $\mathrm{IC}_{50}$ under the level of simultaneous exposure in Capan-1 and MIA PaCa2 lines, while it did not induce any substantial modification in CFPAC-1 line (Figure 2). In Capan-1 and MIA $\mathrm{PaCa} 2$ lines, the calculation of $\mathrm{CI}$ value confirmed the synergism for DCT $\rightarrow$ PMX sequences (Figure 5).

Finally, the sequential exposure to PMX followed by CPT-11 $(\mathrm{PMX} \rightarrow \mathrm{CPT}-11)$ appeared more efficient than the reverse sequence (CPT-11 $\rightarrow$ PMX) in inducing apoptosis in all the lines, but the $\mathrm{IC}_{50}$ values of the $\mathrm{PMX} \rightarrow \mathrm{CPT}-11$ sequence were higher than those of the simultaneous exposure (Figure 2). Moreover, the calculation of the $\mathrm{CI}$ value at effect level obtainable with concentration under the $C_{\max }$ of CPT-11 showed antagonism for both the PMX $\rightarrow$ CPT-11 and CPT-11 $\rightarrow$ PMX sequences in all the lines (Figure 5). These data suggested that for the PMX-CPT-11 combination, the sequential exposure to the drugs does not improve the action in comparison to the simultaneous exposure.

Study of the PMX - CPT-11 combination activity on a large panel of pancreatic cancer cell lines: effect on cell survival, cell cycle, clonogenicity, caspases $3-7$ activation

To confirm the efficacy of PMX-CPT-11 combination, we extended the study to a larger panel of pancreatic cancer cell lines

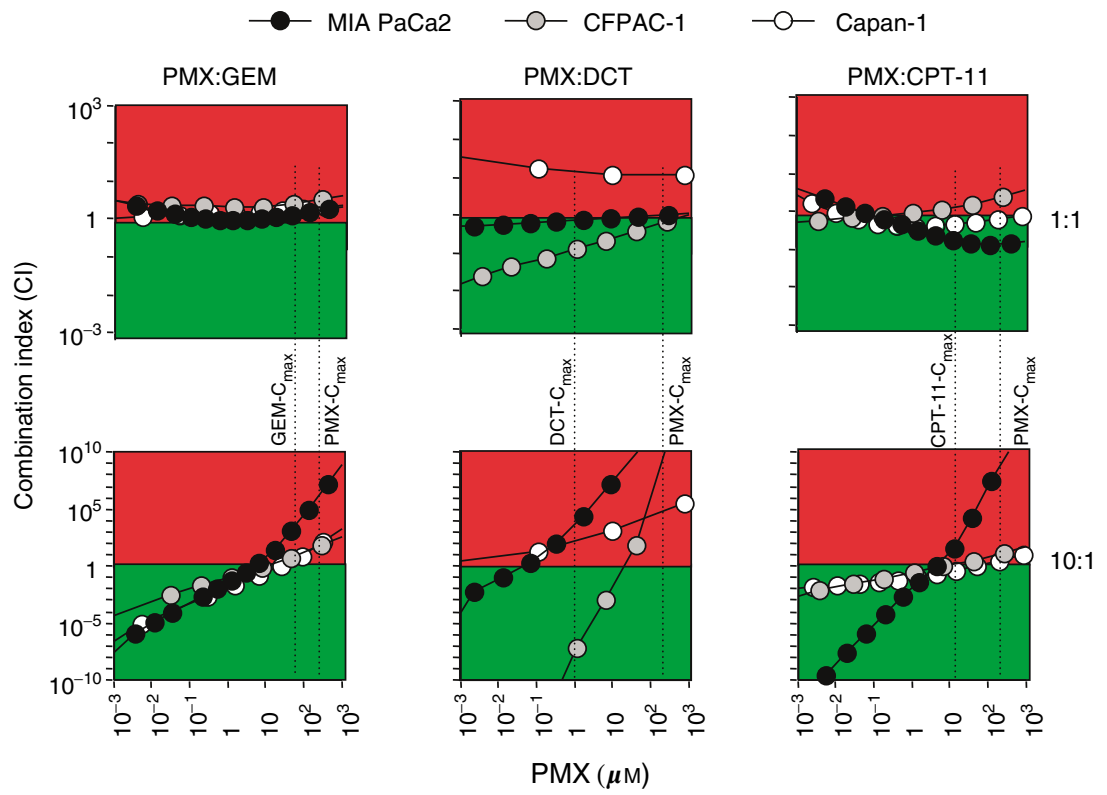

Figure 3 Combination index (Cl) plots of PMX/GEM, PMX/DCT and PMX/CPT-II association in MIA PaCa2, CFPAC-I and Capan- I pancreatic cancer cell lines. Data are represented as concentration/combination index $(\mathrm{Cl})$ plot. The $\mathrm{Cl}$ was calculated in a constant ratio combination experimental design. The I: I and 10: I concentration ratio of PMX/GEM, PMX/DCT and PMX/CPT-II combinations were represented. $\mathrm{Cl}<\mathrm{I}$ (green colour), $\mathrm{Cl}=\mathrm{I}$ and $\mathrm{Cl}>$ I (red colour) indicate synergistic, additive and antagonistic effects, respectively. Dotted lines: $C_{\max }$ of GEM, DCT, CPT-I I and PMX. The plots represent the mean of six experiments. 

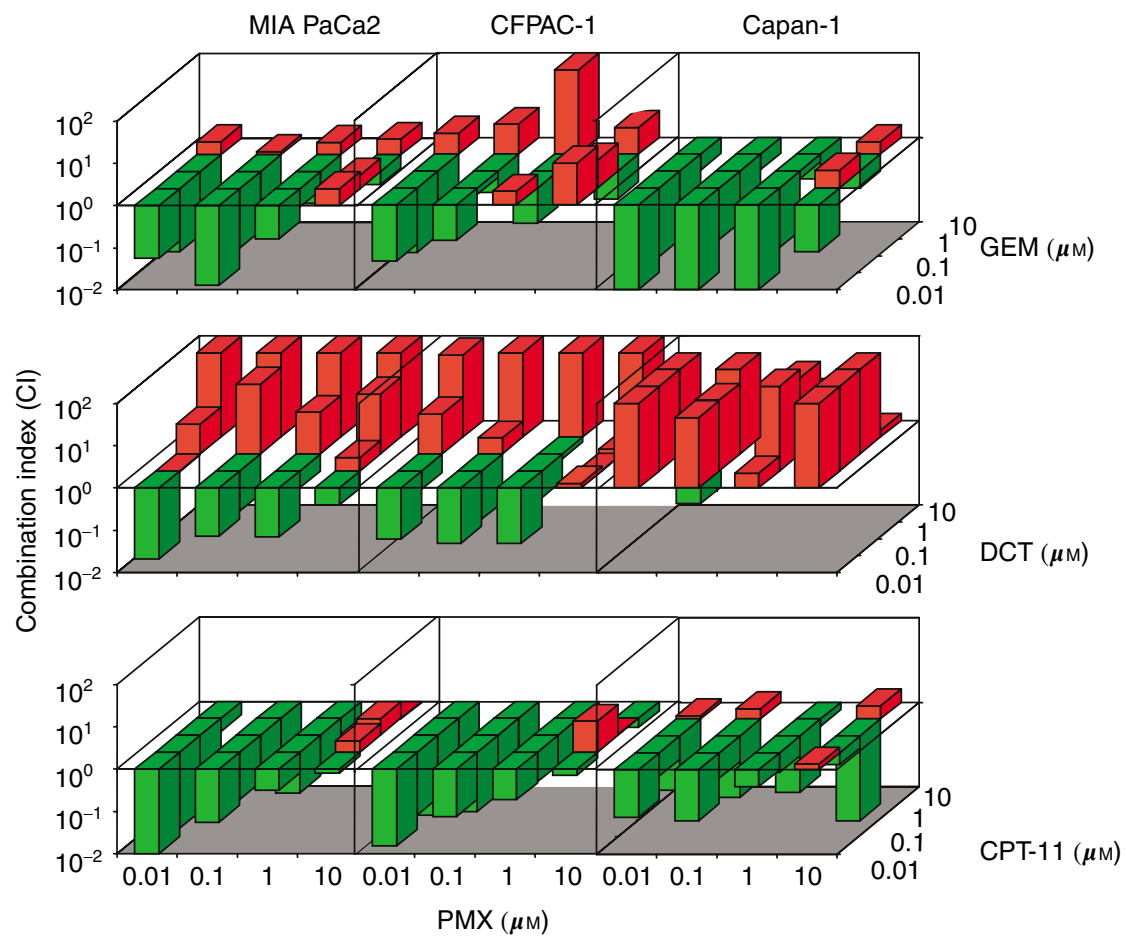

Figure 4 Combination index $(\mathrm{Cl})$ of PMX interaction with GEM, DCT and CPT-I I in a nonconstant ratio combination design. The concentrations of each drug from 0.01 to $10 \mu \mathrm{M}$ were tested. $\mathrm{Cl}<\mathrm{I}$ (green colour), $\mathrm{Cl}=\mathrm{I}$ and $\mathrm{Cl}>\mathrm{I}$ (red colour) indicate synergistic, additive and antagonistic effects, respectively. The data represent the mean of three experiments.

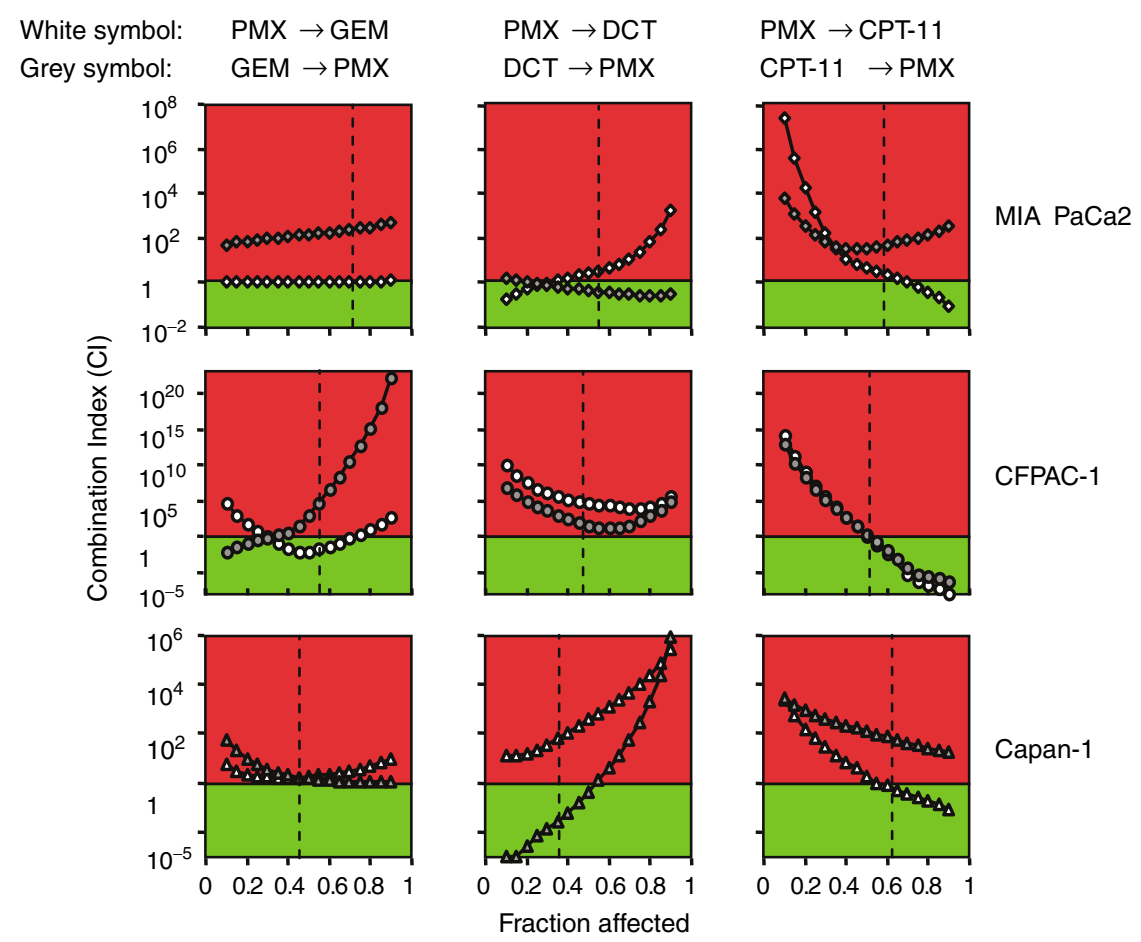

Figure 5 Combination index $(\mathrm{Cl})$ plots of schedule-dependent PMX/GEM, PMX/DCT and PMX/CPT-II combination in MIA PaCa2, CFPAC-I and Capan- I pancreatic cancer cell lines. Cell lines were treated with (a) PMX $(0.00$ I - $100 \mu \mathrm{M})$ for $24 \mathrm{~h}$ followed by GEM, DCT or CPT- I I for $24 \mathrm{~h}$ at I : I ratio (white symbols); (b) the reverse sequence of point (a) (grey symbols). $\mathrm{Cl}<\mathrm{I}$ (green colour), $\mathrm{Cl}=\mathrm{I}$ and $\mathrm{Cl}>\mathrm{I}$ (red colour) indicate synergistic, additive and antagonistic effects, respectively. The data represent the mean of three experiments. Dotted lines: fraction affected at $C_{\max }$ of different drug for each line tested.

using clinically relevant concentrations. Ten pancreatic cancer cell lines (PaCa3, SK-PC 1, PANC-2, MiaPaCa-2 from primary cancer; CFPAC1, PC, HS766T, Capan-1, T3M4, from metastases; A818-4 from ascites) were treated with the PMX $(10 \mu \mathrm{M}) / \mathrm{CPT}-11(1 \mu \mathrm{M})$ combination for $48 \mathrm{~h}$. Cell recovery, viability and apoptosis (cell cycle and caspase 3/7 activation) were analysed. In eight of 10 lines, PMX/CPT-11 significantly reduced cell recovery and increased both the subG1 and caspase $3 / 7$ fraction (Table 1). 
Table I Effect of PMX:CPT-II combination on cell recovery, cell cycle, caspase 3/7 activation: $48 \mathrm{~h}$ exposure

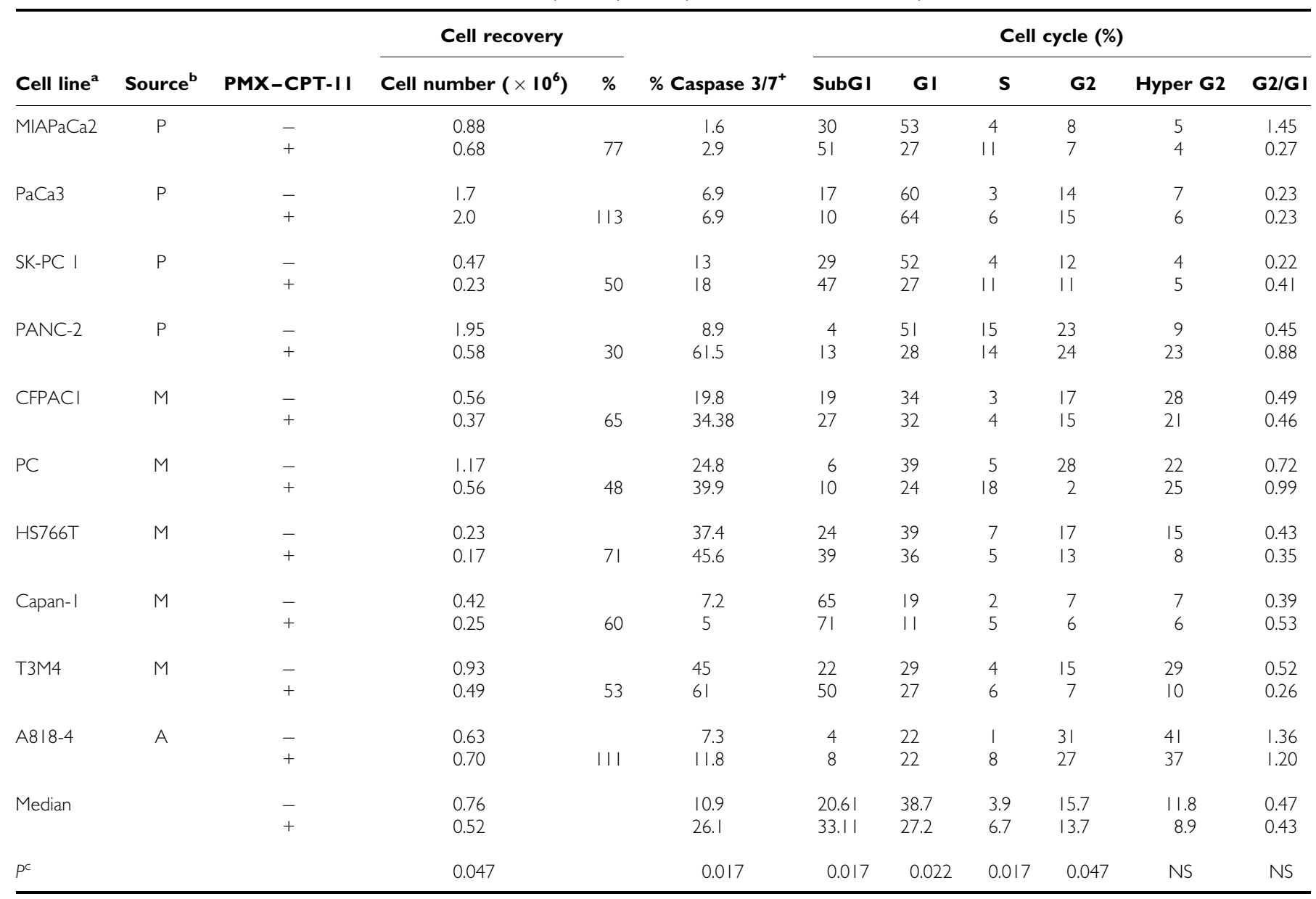

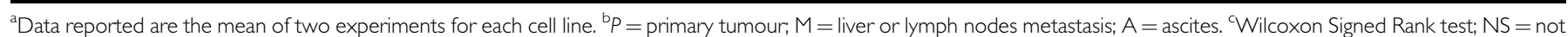
statistically different. PMX = pemetrexed; CPT-II = irinotecan.

To evaluate the cells that have entered into a necrotic or senescent phases during the treatment and that have lost the capacity to reproduce, after the $48 \mathrm{~h}$ drug exposure, the pancreatic cancer cell lines were washed and cultured in a drug-free environment for 5 days. After the wash out period, an increased fraction of subG1 and caspase 3/7 persisted in PMX-CPT-11-pretreated cell lines. Moreover, a significant reduction in the clonogenicity capacity of the lines was evident (Table 2).

\section{In vivo antitumour effect of PMX - CPT-11 combination after GEM treatment in xenografted nude mice}

To evaluate the in vivo antitumour effect of PMX-CPT-11 combination as second-line salvage chemotherapy, CFPAC-1, MIA PaCa2 and PACA3 xenograft tumours established subcutaneously in athymic nude mice were treated with vehicle (PBS) or GEM (days $0-12$ ). Starting from day +12 , the GEM-treated tumours were randomised to be treated with PMX/CPT-11 (day 12-22) or with GEM (days 12-22) (Figure 6). The growth of CFPAC-1 xenografts was completely abolished by i.p. injection of GEM. In detail, at 12 days, the mean volumes were $32 \pm 24$ and $29 \pm 11 \mathrm{~mm}^{3}$ in the two groups receiving GEM, which were significantly smaller than that in control group $\left(516 \pm 133 \mathrm{~mm}^{3}\right.$; $P<0.001)$. The shift of the treatment to PMX/CPT-11 did not change the growth of CFPAC- 1 in comparison to GEM. At 22 days, the mean volumes were $5 \pm 3$ and $20 \pm 15 \mathrm{~mm}^{3}$, respectively, in groups receiving GEM or PMX-CPT-11 $(P=0.89)$, which remained significantly smaller than that in control group $\left(1304+458 \mathrm{~mm}^{3} ; P<0.001\right)$. The inhibition of the growth was maintained even after drug withdrawn. The growth of MIA PaCa2 xenografts was significantly inhibited, but not completely abolished by i.p. injection of GEM. In detail, at 12 days, the mean volumes were $194 \pm 92$ and $178 \pm 29 \mathrm{~mm}^{3}$ in the two groups receiving GEM, which were significantly smaller than that in control group $\left(468 \pm 151 \mathrm{~mm}^{3} ; P<0.01\right)$. The shift to the PMX/ CPT-11 was more effective in inhibiting the growth of MIA PaCa2 than the maintenance of GEM treatment. At 22 days, the mean volumes were $315 \pm 135$ and $138 \pm 33 \mathrm{~mm}^{3}$, respectively, in groups receiving GEM or PMX-CPT-11 $(P=0.05)$ and both remained significantly smaller than that in control group $\left(1122 \pm 334 \mathrm{~mm}^{3}\right.$; $P<0.001)$. Also in MIA PaCa2 xenografts, the effect on the growth was maintained even after drug withdrawn. Similarly to MIA $\mathrm{PaCa} 2$ xenografts, PACA3 xenografts showed a partial sensibility to the GEM action and an increased inhibition of growth after the shift to the PMX/CPT-11 treatment. At 12 days, the mean volumes were $866 \pm 273$ and $770 \pm 216 \mathrm{~mm}^{3}$ in the two groups receiving GEM, which were significantly smaller than that in control group $\left(1610 \pm 445 \mathrm{~mm}^{3} ; P<0.05\right)$. At 22 days, the mean volumes were $1322 \pm 440$ and $798 \pm 171 \mathrm{~mm}^{3}$, respectively, in groups receiving GEM or PMX-CPT-11 $(P=0.05)$ and both remained significantly smaller than that in control group $\left(2147 \pm 463 \mathrm{~mm}^{3} ; P<0.01\right)$.

\section{DISCUSSION}

The aim of the present study was to identify in vitro new drug combinations to be used in clinical testing as salvage chemotherapy 
Table 2 Effect of PMX:CPT-II combination on cell recovery, cell cycle, caspase 3/7 activation and clonogenicity: 5 days after $48 \mathrm{~h}$ exposure

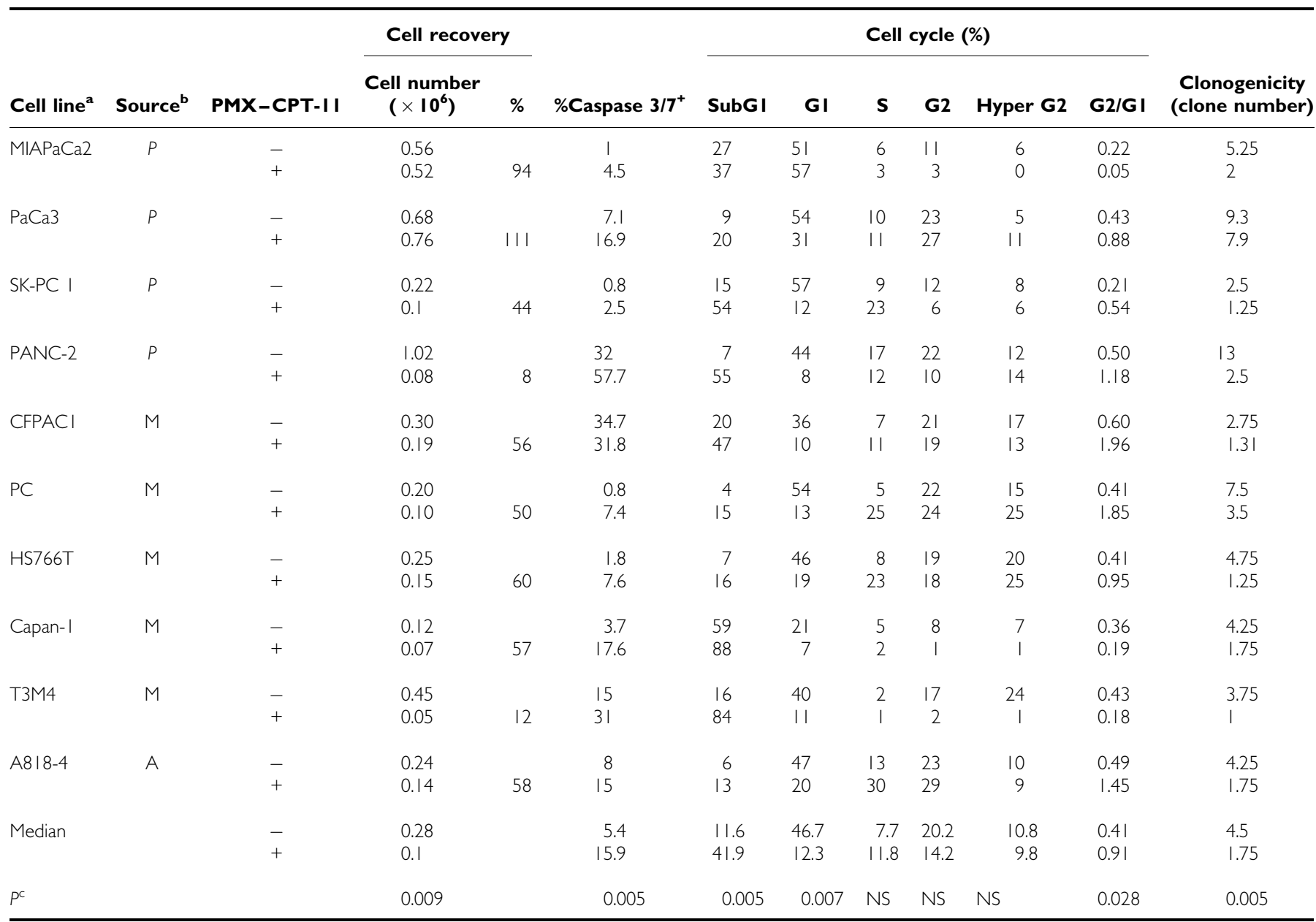

${ }^{a}$ Data reported are the mean of two experiments for each cell line. ${ }^{b} P=$ primary tumour; $M=$ liver or lymph nodes metastasis; $A=$ ascites. ${ }^{~ W i l c o x o n ~}$ Signed Rank test; $N S=$ not statistically different. PMX = pemetrexed; CPT-II = irinotecan.

in pancreatic cancer patients after GEM failure. The PMX and CPT-11 combination showed the strongest schedule-independent synergistic cytotoxic activity. Its efficacy was confirmed in vitro in a large panel of pancreatic cancer cell lines using clinically relevant concentrations and in vivo in three xenograft tumours providing experimental basis for its clinical testing as salvage chemotherapy in pancreatic cancer patients.

Pemetrexed inhibits thymidylate synthase, dihydrofolate reductase, and glycinamide ribonucleotide formyltransferase (Shih et al, 1997), thereby depleting nucleotide pools and blocking DNA synthesis (Tonkinson et al, 1997; Chen et al, 1999). Single-agent $\mathrm{PMX}$ in vivo has demonstrated activity in pancreatic cancer with a response rate of $5.7 \%$, median survival of 6.5 months and 1-year survival of $28 \%$, as reported in a phase II study (Miller et al, 2000; Kindler, 2002). On the basis of these data, together with phase I data showing synergy between GEM and PMX in a broad range of tumours, a phase III study of GEM/PMX combination was conducted on pancreatic cancer patients (Kindler, 2002; Oettle et al, 2005). Unfortunately, the results showed that the combination of PMX and GEM did not improve survival in patients with unresectable locally advanced or metastatic pancreatic cancer with an increase in toxicity compared with GEM monotherapy, but other combinations of PMX should continue to be explored in an effort to further improve the treatment of this chemorefractory disease.

Based on the PMX activity as single agent, we tested PMX in combination with DCT (antimicrotubule agent) and CPT-11 (topoisomerase inhibitors). The combinations of PMX with OXP or RTX were not assessed because a phase II clinical trial with RTX and OXP as salvage chemotherapy in GEM-resistant metastatic pancreatic cancer was already concluded and the results were recently reported (Reni et al, 2006). The in vitro study clearly indicates the PMX and CPT-11 combination as the most active one against pancreatic cancer: (i) the PMX and CPT-11 combination strongly reduced the $\mathrm{IC}_{50}$ in all the three lines tested; (ii) the effect was relevant at concentration that it is possible to achieve in vivo; (iii) the effect was maximum for the relevant clinical concentration ratio of $10: 1$. (iv) the sequential exposure PMX $\rightarrow$ CPT-11 appeared more efficient than the reverse sequence CPT-11 $\rightarrow$ $\mathrm{PMX}$, but the $\mathrm{IC}_{50}$ values of the $\mathrm{PMX} \rightarrow \mathrm{CPT}-11$ sequence remained higher than those of the simultaneous exposure.

The efficacy of PMX-CPT-11 combination was confirmed in a panel of 10 pancreatic cancer cell lines using clinically relevant concentrations (PMX $10 \mu \mathrm{M}$; CPT-11 $1 \mu \mathrm{m}$ ). Based on the data obtained in vitro, we also tested the efficacy PMX/CPT-11 combination in vivo in CFPAC-1, MIA $\mathrm{PaCa} 2$ and PACA3 xenograft tumours established subcutaneously in athymic nude mice. Since the objective was to provide experimental basis for use in clinical trial as second-line salvage chemotherapy, we design to treat mice with PMX/CPT-11 after the GEM therapy and not as first-line therapy. Pemetrexed/CPT-11 combination showed the ability to further inhibit the cancer growth in the two lines partially responsive to GEM and to maintain the block of proliferation in the GEM full responsive line. Even if the in vivo 


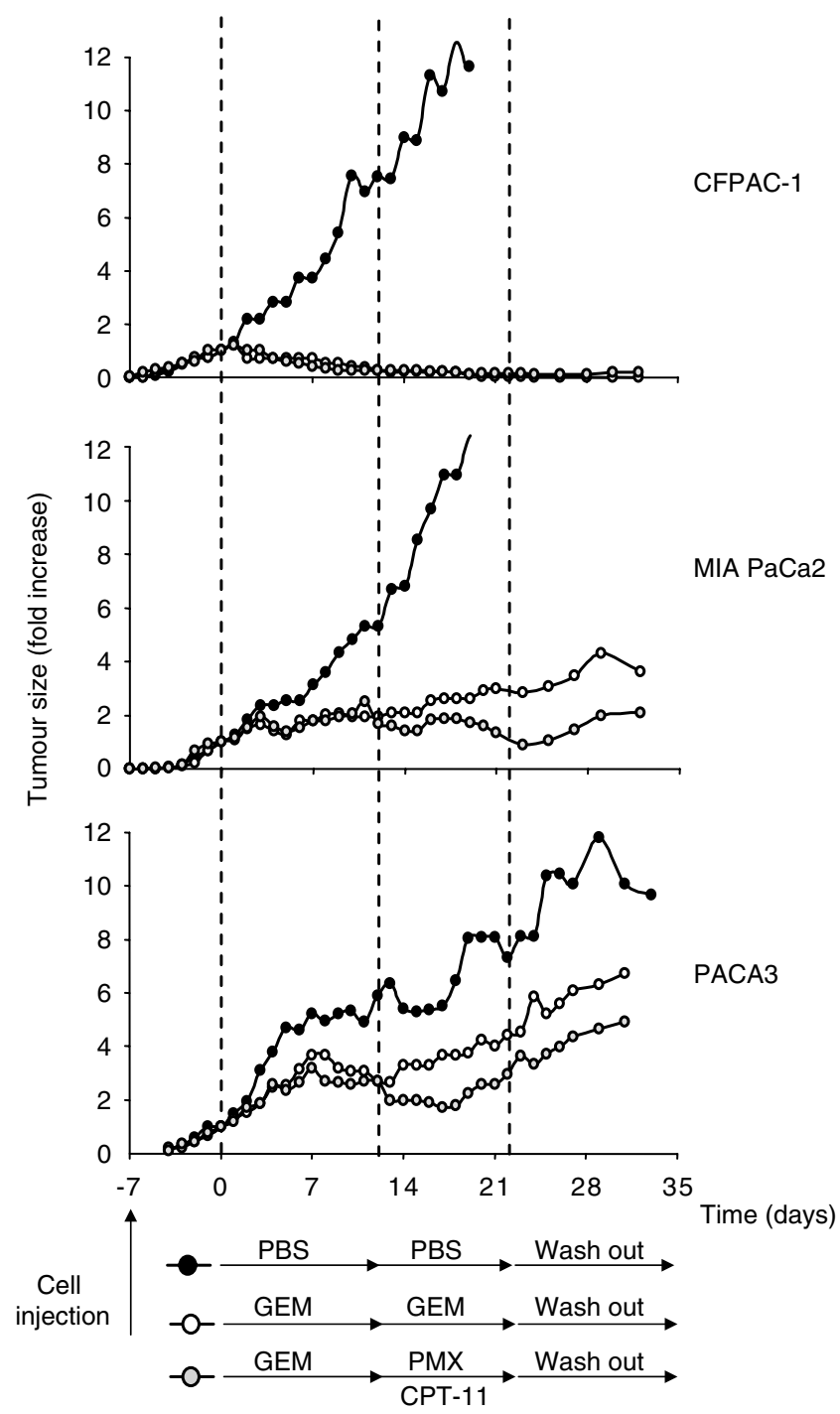

Figure 6 Antitumour activity of PMX/CPT-II combination against pancreatic cancer xenografts. MIA PaCa2, CFPAC-I and PACA3 xenograft tumours established subcutaneously in athymic nude mice were randomised to treatment groups ( $n=5$ mice pergroup). The treatment groups were untreated controls (black symbol: PBS i.p.), GEM alone (white symbol: $150 \mathrm{mg} \mathrm{kg}^{-1}$ i.p. on days $\left.0,+3,+6,+9,+12,+15,+18,+21\right)$ or PMX/CPT-I I after GEM treatment (grey symbol: GEM I $50 \mathrm{mg} \mathrm{kg}^{-1}$ i.p. on days $0,+3,+6,+9$; $\mathrm{PMX} 100 \mathrm{mg} \mathrm{kg}^{-1}$ i.p. on every day starting from day +12 until day +21 ; CPT-1 $150 \mathrm{mg} \mathrm{kg}^{-1}$ i.p. on days +12 and + 17) Data are expressed as the median change (fold increase) in tumour volume relative to volume on day 0 , when treatment was initiated (MIA $\mathrm{PaCa} 2=89.288 \mathrm{~mm}^{3} ;$ CFPAC $-\mathrm{I}=65.46 \mathrm{~mm}^{3} ;$ PACA3 $\left.=261.87 \mathrm{~mm}^{3}\right)$.

results of PMX/CPT-11 treatment could appear quantitatively disappointing, starting from the presence of GEM pretreatment, they should be considered relevant.

The PMX/CPT-11 combination respects the four principles underlying the design of chemotherapy combination. First, each agent in a regimen has shown to be independently active against the pancreatic tumour. In fact, not only PMX, as above reported, has demonstrated to be active as single agent but CPT-11 also has demonstrated activity, although modest, in pancreatic cancer (Wagener et al, 1995; Klapdor and Fenner, 2000; Pizzolato and Saltz, 2003). Unfortunately, a recently reported phase III trial of GEM with or without CPT-11 revealed no survival benefit (Rocha Lima et al, 2004; Stathopoulos et al, 2006) but other combinations of CPT-11 should continue to be explored in an effort to further improve the treatment of this chemorefractory disease (Taieb et al, 2006). Secondly, each drug in this combination has an independent mechanism of action. In fact, PMX is an antimetabolite while CPT-11 is a selective DNA topoisomerase I inhibitor, targeting different steps along different biochemical pathways. Pavillard et al (1998) have shown an inverse relationship between thymidylate synthase activity and irinotecan-induced cleavable complex formation, which suggests a potential mechanism whereby synergy between PMX and CPT-11 might be expected to occur. Third, there is no crossresistance, at least in vitro, between PMX and CPT-11 and also among these two drugs and GEM. Fourth, PMX and CPT-11 have a different dose-limiting toxicity. Both the susceptibility to PMX/CPT-11 combination even in GEM-resistant lines and the evidence from previous works that in vivo full doses of PMX and CPT-11 are well tolerated in several small phase I and II trials in pretreated colorectal cancer patients (Grothey and Schmoll, 2001; Rowinsky et al, 2007) encourage the use of these two drugs in clinical experimental protocols as second-line treatment for pancreatic cancer.

In our study we also reported the evaluation of PMX combined with GEM, even if we looked for GEM-free protocol. The reason was that this combination represents a sort of reference point, since preclinical and clinical studies have shown synergy in a broad range of tumours including pancreatic cancer (Adjei et al, 2000; Giovannetti et al, 2004; Dy et al, 2005; Oettle et al, 2005). Consequently, the evidence of a major efficiency of the PMX-CPT-11 in comparison with the PMX-GEM should be considered as a further reason for its clinical testing. Of note, the phase III clinical study of PMX-GEM combination showed that the use of GEM intravenously over $\sim 30 \mathrm{~min}$ followed $\sim 90$ min later by PMX does not improve survival in patients with unresectable locally advanced or metastatic pancreatic cancer (Kindler, 2002; Oettle et al, 2005). The absence of preclinical data of PMX-GEM combination specifically on pancreatic cancer was probably one of the cause of the failure of the phase III study. In fact, the use of the sequence was based on studies demonstrating synergistic cytotoxicity when GEM exposure precedes PMX exposure in HCT-8-cultured human colon cancer cell lines (Adjei et al, 2000) and on similar results obtained in LoVo, WiDr and LRWZ cells (Tesei et al, 2002). However, other reports proposed synergistic cytotoxicity for the opposite sequence PMX exposure followed $24 \mathrm{~h}$ later by GEM exposure (Tonkinson et al, 1999; Giovannetti et al, 2004). Our study suggested that the highest chemotherapeutic activity against MIA PaCa-2, PANC-1 and Capan-1 cells for PMX-GEM combination is observed with the sequence PMX $\rightarrow$ GEM, exactly the opposite of that used in clinical trial. Since the patterns of interaction with these two agents is cell line and tissue specific, the limited availability of preclinical data on PMX-GEM combination on pancreatic cancer likely hampered the rational design of the clinical study contributing to its failure.

To date, different options based on GEM are available for firstline treatment of pancreatic cancer (Burris et al, 1997; Reni et al, 2005). However, GEM-based chemotherapy yields a very limited disease control, and progression usually occurs within a few months after first-line treatment starts. In spite of progressive disease, about half of the patients maintain a good performance status and are willing to undergo further treatment. As no standard therapeutic option exists and scarce information on the impact on outcome of salvage therapy is available from the literature, studies attempting to widen the therapeutic armamentarium against this disease are warranted. Based on the result of our study, the PMX/ CPT-11 association appears a promising GEM-free drug combination and we think that our results provide the experimental basis for its clinical testing as salvage chemotherapy in pancreatic cancer patients. 


\section{ACKNOWLEDGEMENTS}

This work was supported by Awards from Fondazione Siemens Italia to VDC (Milan, Italy), Fondazione Cariverona to AS (Verona,
Italy), MIUR 2005 (VDC, AS), AIRC (VDC, AS), and Ministero Sanità (AS, LP).

\section{REFERENCES}

Abbruzzese JL, Grunewald R, Weeks EA, Gravel D, Adams T, Nowak B, Mineishi S, Tarassoff P, Satterlee W, Raber MN (1991) A phase I clinical, plasma, and cellular pharmacology study of gemcitabine. J Clin Oncol 9: $491-498$

Adjei AA, Erlichman C, Sloan JA, Reid JM, Pitot HC, Goldberg RM, Peethambaram P, Atherton P, Hanson LJ, Alberts SR, Jett J (2000) Phase and pharmacologic study of sequences of gemcitabine and the multitargeted antifolate agent in patients with advanced solid tumors. J Clin Oncol 18: $1748-1757$

Beale P, Judson I, Hanwell J, Berry C, Aherne W, Hickish T, Martin P, Walker M (1998) Metabolism, excretion and pharmacokinetics of a single dose of $\left[{ }^{14} \mathrm{C}\right]$-raltitrexed in cancer patients. Cancer Chemother Pharmacol 42: $71-76$

Beger HG, Rau B, Gansauge F, Poch B, Link KH (2003) Treatment of pancreatic cancer: challenge of the facts. World J Surg 27: 1075-1084

Berlin JD, Catalano P, Thomas JP, Kugler JW, Haller DG, Benson III AB (2002) Phase III study of gemcitabine in combination with fluorouracil vs gemcitabine alone in patients with advanced pancreatic carcinoma: Eastern Cooperative Oncology Group Trial E2297. J Clin Oncol 20: $3270-3275$

Bramhall SR, Rosemurgy A, Brown PD, Bowry C, Buckels JA (2001) Marimastat as first-line therapy for patients with unresectable pancreatic cancer: a randomized trial. J Clin Oncol 19: 3447-3455

Bramhall SR, Schulz J, Nemunaitis J, Brown PD, Baillet M, Buckels JA (2002) A double-blind placebo-controlled, randomised study comparing gemcitabine and marimastat with gemcitabine and placebo as first line therapy in patients with advanced pancreatic cancer. $\mathrm{Br} J$ Cancer 87: $161-167$

Burris H, Irvin R, Kuhn J, Kalter S, Smith L, Shaffer D, Fields S, Weiss G, Eckardt J, Rodriguez G (1993) Phase I clinical trial of taxotere administered as either a 2- or 6-h intravenous infusion. J Clin Oncol 11: $950-958$

Burris III HA, Moore MJ, Andersen J, Green MR, Rothenberg ML, Modiano MR, Cripps MC, Portenoy RK, Storniolo AM, Tarassoff P, Nelson R, Dorr FA, Stephens CD, Von Hoff DD (1997) Improvements in survival and clinical benefit with gemcitabine as first-line therapy for patients with advanced pancreas cancer: a randomized trial. J Clin Oncol 15: $2403-2413$

Cantore M, Rabbi C, Fiorentini G, Oliani C, Zamagni D, Iacono C, Mambrini A, Del Freo A, Manni A (2004) Combined irinotecan and oxaliplatin in patients with advanced pre-treated pancreatic cancer. Oncology 67: $93-97$

Chabot GG (1997) Clinical pharmacokinetics of irinotecan. Clin Pharmacokinet 33: $245-259$

Chen VJ, Bewley JR, Andis SL, Schultz RM, Iversen PW, Shih C, Mendelsohn LG, Seitz DE, Tonkinson JL (1999) Cellular pharmacology of MTA: a correlation of MTA-induced cellular toxicity and in vitro enzyme inhibition with its effect on intracellular folate and nucleoside triphosphate pools in CCRF-CEM cells. Semin Oncol 26: 48-54

Chou TC, Motzer RJ, Tong Y, Bosl GJ (1994) Computerized quantitation of synergism and antagonism of taxol, topotecan, and cisplatin against human teratocarcinoma cell growth: a rational approach to clinical protocol design. J Natl Cancer Inst 86: 1517-1524

Clarke SJ, Hanwell J, de Boer M, Planting A, Verweij J, Walker M, Smith R, Jackman AL, Hughes LR, Harrap KR, Kennealey GT, Judson IR (1996) Phase I trial of ZD1694, a new folate-based thymidylate synthase inhibitor, in patients with solid tumors. J Clin Oncol 14: 1495-1503

Cullinan S, Moertel CG, Wieand HS, Schutt AJ, Krook JE, Foley JF, Norris BD, Kardinal CG, Tschetter LK, Barlow JF (1990) A phase III trial on the therapy of advanced pancreatic carcinoma. Evaluations of the Mallinson regimen and combined 5-fluorouracil, doxorubicin, and cisplatin. Cancer 65: $2207-2212$

Culy CR, Clemett D, Wiseman LR (2000) Oxaliplatin. A review of its pharmacological properties and clinical efficacy in metastatic colorectal cancer and its potential in other malignancies. Drugs 60: 895-924
Ducreux M, Rougier P, Pignon JP, Douillard JY, Seitz JF, Bugat R, Bosset JF, Merouche Y, Raoul JL, Ychou M, Adenis A, Berthault-Cvitkovic F, Luboinski M (2002) A randomised trial comparing 5-FU with 5-FU plus cisplatin in advanced pancreatic carcinoma. Ann Oncol 13: 1185-1191

Dy GK, Suri A, Reid JM, Sloan JA, Pitot HC, Alberts SR, Goldberg RM, Atherton PJ, Hanson LJ, Burch PA, Rubin J, Erlichman C, Adjei AA (2005) A phase IB study of the pharmacokinetics of gemcitabine and pemetrexed, when administered in rapid sequence to patients with advanced solid tumors. Cancer Chemother Pharmacol 55: 522-530

Edelman MJ, Quam H, Mullins B (2001) Interactions of gemcitabine, carboplatin and paclitaxel in molecularly defined non-small-cell lung cancer cell lines. Cancer Chemother Pharmacol 48: $141-144$

Extra JM, Rousseau F, Bruno R, Clavel M, Le Bail N, Marty M (1993) Phase I and pharmacokinetic study of Taxotere (RP 56976; NSC 628503) given as a short intravenous infusion. Cancer Res 53: 1037-1042

Gamelin E, Boisdron-Celle M, Delva R, Regimbeau C, Cailleux PE, Alleaume C, Maillet ML, Goudier MJ, Sire M, Person-Joly MC, Maigre M, Maillart P, Fety R, Burtin P, Lortholary A, Dumesnil Y, Picon L, Geslin J, Gesta P, Danquechin-Dorval E, Larra F, Robert J (1998) Long-term weekly treatment of colorectal metastatic cancer with fluorouracil and leucovorin: results of a multicentric prospective trial of fluorouracil dosage optimization by pharmacokinetic monitoring in 152 patients. J Clin Oncol 16: $1470-1478$

Giovannetti E, Mey V, Danesi R, Mosca I, Del Tacca M (2004) Synergistic cytotoxicity and pharmacogenetics of gemcitabine and pemetrexed combination in pancreatic cancer cell lines. Clin Cancer Res 10: $2936-2943$

Grothey A, Schmoll HJ (2001) New chemotherapy approaches in colorectal cancer. Curr Opin Oncol 13: 275-286

Heinemann V (2002) Gemcitabine in the treatment of advanced pancreatic cancer: a comparative analysis of randomized trials. Semin Oncol 29: $9-16$

Hui YF, Reitz J (1997) Gemcitabine: a cytidine analogue active against solid tumors. Am J Health Syst Pharm 54: 162-170; quiz 197-198

Jodrell DI, Stewart M, Aird R, Knowles G, Bowman A, Wall L, McLean C (2001) 5-Fluorouracil steady state pharmacokinetics and outcome in patients receiving protracted venous infusion for advanced colorectal cancer. Br J Cancer 84: 600-603

Judson I, Maughan T, Beale P, Primrose J, Hoskin P, Hanwell J, Berry C, Walker M, Sutcliffe F (1998) Effects of impaired renal function on the pharmacokinetics of raltitrexed (Tomudex ZD1694). Br J Cancer 78: $1188-1193$

Kindler HL (2002) The pemetrexed/gemcitabine combination in pancreatic cancer. Cancer 95: $928-932$

Klapdor R, Fenner C (2000) Irinotecan(Campto R): efficacy as third/forth line therapy in advanced pancreatic cancer. Anticancer Res 20: $5209-5212$

Lionetto R, Pugliese V, Bruzzi P, Rosso R (1995) No standard treatment is available for advanced pancreatic cancer. Eur J Cancer 31 A: 882-887

Maisey N, Chau I, Cunningham D, Norman A, Seymour M, Hickish T, Iveson T, O’Brien M, Tebbutt N, Harrington A, Hill M (2002) Multicenter randomized phase III trial comparing protracted venous infusion (PVI) fluorouracil (5-FU) with PVI 5-FU plus mitomycin in inoperable pancreatic cancer. J Clin Oncol 20: $3130-3136$

Milella M, Gelibter A, Di Cosimo S, Bria E, Ruggeri EM, Carlini P, Malaguti P, Pellicciotta M, Terzoli E, Cognetti F (2004) Pilot study of celecoxib and infusional 5-fluorouracil as second-line treatment for advanced pancreatic carcinoma. Cancer 101: $133-138$

Miller KD, Picus J, Blanke C, John W, Clark J, Shulman LN, Thornton D, Rowinsky E, Loehrer Sr PJ (2000) Phase II study of the multitargeted antifolate LY231514 (ALIMTA, MTA, pemetrexed disodium) in patients with advanced pancreatic cancer. Ann Oncol 11: 101-103

Mishra G, Butler J, Ho C, Melin S, Case LD, Ennever PR, Magrinat GC, Bearden JD, Minotto DC, Howerton R, Levine E, Blackstock AW (2005) Phase II trial of induction gemcitabine/CPT-11 followed 
by a twice-weekly infusion of gemcitabine and concurrent external beam radiation for the treatment of locally advanced pancreatic cancer. $A m J$ Clin Oncol 28: $345-350$

Moore MJ, Hamm J, Dancey J, Eisenberg PD, Dagenais M, Fields A, Hagan K, Greenberg B, Colwell B, Zee B, Tu D, Ottaway J, Humphrey R, Seymour L (2003) Comparison of gemcitabine vs the matrix metalloproteinase inhibitor BAY 12-9566 in patients with advanced or metastatic adenocarcinoma of the pancreas: a phase III trial of the National Cancer Institute of Canada Clinical Trials Group. J Clin Oncol 21: 3296-3302

O'Dwyer PJ, Nelson K, Thornton DE (1999) Overview of phase II trials of MTA in solid tumors. Semin Oncol 26: 99-104

Oettle H, Arnold D, Esser M, Huhn D, Riess H (2000) Paclitaxel as weekly second-line therapy in patients with advanced pancreatic carcinoma. Anticancer Drugs 11: 635-638

Oettle H, Richards D, Ramanathan RK, van Laethem JL, Peeters M, Fuchs M, Zimmermann A, John W, Von Hoff D, Arning M, Kindler HL (2005) A phase III trial of pemetrexed plus gemcitabine $v s$ gemcitabine in patients with unresectable or metastatic pancreatic cancer. Ann Oncol 16: $1639-1645$

Pavillard V, Formento P, Rostagno P, Formento JL, Fischel JL, Francoual M, Etienne MC, Milano G (1998) Combination of irinotecan (CPT11) and 5fluorouracil with an analysis of cellular determinants of drug activity. Biochem Pharmacol 56: 1315-1322

Pazdur R, Kudelka AP, Kavanagh JJ, Cohen PR, Raber MN (1993) The taxoids: paclitaxel (Taxol) and docetaxel (Taxotere). Cancer Treat Rev 19: $351-386$

Peters GJ, van der Wilt CL, van Moorsel CJ, Kroep JR, Bergman AM, Ackland SP (2000) Basis for effective combination cancer chemotherapy with antimetabolites. Pharmacol Ther 87: 227-253

Pizzolato JF, Saltz LB (2003) Irinotecan (Campto) in the treatment of pancreatic cancer. Expert Rev Anticancer Ther 3: 587-593

Reni M, Cordio S, Milandri C, Passoni P, Bonetto E, Oliani C, Luppi G, Nicoletti R, Galli L, Bordonaro R, Passardi A, Zerbi A, Balzano G, Aldrighetti L, Staudacher C, Villa E, Di Carlo V (2005) Gemcitabine vs cisplatin, epirubicin, fluorouracil, and gemcitabine in advanced pancreatic cancer: a randomised controlled multicentre phase III trial. Lancet Oncol 6: 369 - 376

Reni M, Panucci MG, Passoni P, Bonetto E, Nicoletti R, Ronzoni M, Zerbi A, Staudacher C, Di Carlo V, Villa E (2004) Salvage chemotherapy with mitomycin, docetaxel, and irinotecan (MDI regimen) in metastatic pancreatic adenocarcinoma: a phase I and II trial. Cancer Invest 22: $688-696$

Reni M, Pasetto L, Aprile G, Cordio S, Bonetto E, Dell'Oro S, Passoni P, Piemonti L, Fugazza C, Luppi G, Milandri C, Nicoletti R, Zerbi A, Balzano G, Di Carlo V, Brandes AA (2006) Raltitrexed-eloxatin salvage chemotherapy in gemcitabine-resistant metastatic pancreatic cancer. $\mathrm{Br} J$ Cancer 94: $785-791$

Rinaldi DA (1999) Overview of phase I trials of multitargeted antifolate (MTA, LY231514). Semin Oncol 26: 82-88

Rocha Lima CM, Green MR, Rotche R, Miller Jr WH, Jeffrey GM, Cisar LA, Morganti A, Orlando N, Gruia G, Miller LL (2004) Irinotecan plus gemcitabine results in no survival advantage compared with gemcitabine monotherapy in patients with locally advanced or metastatic pancreatic cancer despite increased tumor response rate. J Clin Oncol 22: 3776 - 3783

Rothenberg ML, Kuhn JG, Burris III HA, Nelson J, Eckardt JR, TristanMorales M, Hilsenbeck SG, Weiss GR, Smith LS, Rodriguez GI (1993) Phase I and pharmacokinetic trial of weekly CPT-11. J Clin Oncol 11: 2194- 2204

Rowinsky EK, Beeram M, Hammond LA, Schwartz G, De Bono J, Forouzesh B, Chu Q, Latz JE, Hong S, John W, Nguyen B (2007) A phase I and pharmacokinetic study of pemetrexed plus irinotecan in patients with advanced solid malignancies. Clin Cancer Res 13: 532-539
Schnall SF, Macdonald JS (1996) Chemotherapy of adenocarcinoma of the pancreas. Semin Oncol 23: 220-228

Shih C, Chen VJ, Gossett LS, Gates SB, MacKellar WC, Habeck LL, Shackelford KA, Mendelsohn LG, Soose DJ, Patel VF, Andis SL, Bewley JR, Rayl EA, Moroson BA, Beardsley GP, Kohler W, Ratnam M, Schultz RM (1997) LY231514, a pyrrolo[2,3-d]pyrimidine-based antifolate that inhibits multiple folate-requiring enzymes. Cancer Res 57: $1116-1123$

Stathopoulos GP, Syrigos K, Aravantinos G, Polyzos A, Papakotoulas P, Fountzilas G, Potamianou A, Ziras N, Boukovinas J, Varthalitis J, Androulakis N, Kotsakis A, Samonis G, Georgoulias V (2006) A multicenter phase III trial comparing irinotecan-gemcitabine (IG) with gemcitabine $(\mathrm{G})$ monotherapy as first-line treatment in patients with locally advanced or metastatic pancreatic cancer. $\mathrm{Br}$ J Cancer 95: $587-592$

Storniolo AM, Enas NH, Brown CA, Voi M, Rothenberg ML, Schilsky R (1999) An investigational new drug treatment program for patients with gemcitabine: results for over 3000 patients with pancreatic carcinoma. Cancer 85: 1261 - 1268

Symon Z, Davis M, McGinn CJ, Zalupski MM, Lawrence TS (2002) Concurrent chemoradiotherapy with gemcitabine and cisplatin for pancreatic cancer: from the laboratory to the clinic. Int J Radiat Oncol Biol Phys 53: $140-145$

Taieb J, Lecomte T, Aparicio T, Asnacios A, Mansourbakht T, Artru P, Fallik D, Spano J, Landi B, Lledo G, Desrame J (2006) FOLFIRI.3, a new regimen combining 5-fluorouracil, folinic acid and irinotecan, for advanced pancreatic cancer: results of an Association des GastroEnterologues Oncologues (Gastroenterologist Oncologist Association) multicenter phase II study. Ann Oncol

Tesei A, Ricotti L, De Paola F, Amadori D, Frassineti GL, Zoli W (2002) In vitro schedule-dependent interactions between the multitargeted antifolate LY231514 and gemcitabine in human colon adenocarcinoma cell lines. Clin Cancer Res 8: 233 - 239

Tolis C, Peters GJ, Ferreira CG, Pinedo HM, Giaccone G (1999) Cell cycle disturbances and apoptosis induced by topotecan and gemcitabine on human lung cancer cell lines. Eur J Cancer 35: 796-807

Tonkinson JL, Marder P, Andis SL, Schultz RM, Gossett LS, Shih C, Mendelsohn LG (1997) Cell cycle effects of antifolate antimetabolites: implications for cytotoxicity and cytostasis. Cancer Chemother Pharmacol 39: $521-531$

Tonkinson JL, Worzalla JF, Teng CH, Mendelsohn LG (1999) Cell cycle modulation by a multitargeted antifolate, LY231514, increases the cytotoxicity and antitumor activity of gemcitabine in HT29 colon carcinoma. Cancer Res 59: 3671 - 3676

Ulrich-Pur H, Raderer M, Verena Kornek G, Schull B, Schmid K, Haider K, Kwasny W, Depisch D, Schneeweiss B, Lang F, Scheithauer W (2003) Irinotecan plus raltitrexed $v s$ raltitrexed alone in patients with gemcitabine-pretreated advanced pancreatic adenocarcinoma. $\mathrm{Br} J$ Cancer 88: $1180-1184$

Van Cutsem E, van de Velde H, Karasek P, Oettle H, Vervenne WL, Szawlowski A, Schoffski P, Post S, Verslype C, Neumann H, Safran H, Humblet Y, Perez Ruixo J, Ma Y, Von Hoff D (2004) Phase III trial of gemcitabine plus tipifarnib compared with gemcitabine plus placebo in advanced pancreatic cancer. J Clin Oncol 22: 1430-1438

van Moorsel CJ, Pinedo HM, Veerman G, Bergman AM, Kuiper CM, Vermorken JB, van der Vijgh WJ, Peters GJ (1999) Mechanisms of synergism between cisplatin and gemcitabine in ovarian and non-smallcell lung cancer cell lines. Br J Cancer 80: $981-990$

Wagener DJ, Verdonk HE, Dirix LY, Catimel G, Siegenthaler P, Buitenhuis M, Mathieu-Boue A, Verweij J (1995) Phase II trial of CPT-11 in patients with advanced pancreatic cancer, an EORTC early clinical trials group study. Ann Oncol 6: 129-132 